\title{
Prevalence and Post-exposure Prophylaxis use for Needlestick Injuries among Health Care Providers in a Tertiary Care Hospital in Kochi, India
}

\author{
Arun Kumar Krishnan', Gireesh Kumar KS1, Srinath Kumar TS², Sreekrishnan TP1, Vijay Kumar, Sumi Soman ${ }^{4}$ \\ 'Department of Emergency Medicine, Amrita Institute of Medical Sciences, Amrita Vishwa Vidyapeetham, Kochi, India \\ 2Departmnt of Emergency Medicine, Narayana Hospital, Hosur Main Road, Bangalore, India \\ ${ }^{3}$ Department of Public Health Dentistry, Amrita School of Dentistry, Amrita Vishwa Vidyapeetham, Kochi, India \\ ${ }^{4}$ Department of Public Health, Amrita Institute of Medical Sciences, Amrita Vishwa Vidyapeetham, Kochi, India
}

\begin{abstract}
Aim: The post-exposure prophylaxis (PEP) protocol in needlestick injuries (NSIs) associated with human immunodeficiency virus (HIV) needs to be evaluated in a developing country like India. The aim of this study was to assess the prevalence of NSI and PEP use for HIV exposure in NSIs among health care providers (HPs) in India.

Materials and Methods: A cross-sectional, institution-based study was conducted among HPs in Amrita Institute of Medical Sciences, Kochi, India. Secondary data for 8 years were recorded. The study population included HPs who had NSIs and who reported to the Emergency Department of the hospital. Descriptive statistics and logistic regression analysis were used.

Results: A total of 949 self-reported cases of NSIs from January 2006 to December 2014 were reported, of which $42.9 \%$ were from staff nurses. HPs employed in general/specialty wards (32.5\%) had the highest NSI incidence rate. In total, $67.7 \%$ of the NSIs were moderately deep, while $22.6 \%$ of them were superficial. The commonest device involved was the hypodermic needle (36.7\%). Most NSIs occurred during "post-procedure work-up" (64\%). Further, 32 HPs had received NSIs from known HIV seropositive patients. Totally, $62.5 \%$ of the HPs involved were staff nurses, with a mean age of 26 years. Of the $32 \mathrm{HPs}, 28$ were given prophylactic triple-drug anti-retroviral treatment. All $28 \mathrm{HPs}$ were followed up for 6 months, and no seropositivity was reported.

Conclusion: The present study shows the high prevalence of NSIs among HPs, particularly among staff nurses. HPs have always known to be at risk of contracting acquired infectious diseases. In light of new emerging communicable diseases with new or unknown pathogens as causative agents, the prevention of NSIs among HPs has acquired significant value. Periodic health education campaigns should be promoted, and strict adherence to standard precautionary protocols should be made mandatory to prevent and minimize the incidence of NSIs among HPs. Periodic updates about PEP should also be made to raise awareness among HPs. (Eurasian J Emerg Med 2016; 15: 73-7)
\end{abstract}

Keywords: Needlestick injuries, health care providers, post-exposure prophylaxis, emergency department

\section{Introduction}

Health care providers (HPs) are at a higher risk of occupational exposure to blood-borne infections through percutaneous exposure. The World Health Organization has stated that worldwide, nearly three million HPs experience such an incident (1). Around 60 pathogens can be transmitted through needlestick injuries (NSIs), of which human immunodeficiency virus (HIV) tops the list (2). NSIs have a $0.3 \%$ risk of transmitting HIV, which is the second highest (3).
Around $57 \%$ of HPs had multiple unreported NSIs in the preceding 12 months, which highlights a negligence seen among HPs (4). However, previous studies have suggested that anti-retroviral treatment (ART) reduces the risk of HIV transmission by $81 \%$ following occupational exposure (5). Limited epidemiological studies regarding the risk and circumstances of NSIs among HPs have been identified in developing countries; the use of post-exposure prophylaxis (PEP) has also been identified. The availability of similar epidemiological data will help in formulating an effective prophylactic strat-

Correspondence to: Arun Kumar Krishnan e-mail: knowaboutarun@gmail.com 
egy against NSIs in India. Hence, we conducted this study with the following objectives:

(a) To assess the prevalence of NSIs among HPs

(b) To assess PEP use among HPs following HIV exposure in NSIs

\section{Materials and Methods}

A cross-sectional study was conducted among HPs in Amrita Institute of Medical Sciences, Kochi, India to assess the prevalence of NSIs and PEP use among HPs following HIV exposure. This study was conducted at the Emergency Department (ED) and Infection Control Department in AIMS. This is a tertiary care institution with an average number of in-patients of 25,000 per year and employs approximately $2500 \mathrm{HPs}$. Institutional ethical committee approval was obtained prior to the commencement of the study. The study population selected was HPs comprising doctors, staff nurses, nursing assistants, health care volunteers, lab workers, students, and paramedical staff who had a documented occupational/percutaneous exposure by a needlestick. All NSIs were self-reported to the ED from January 2006 to December 2014, which were systematically recorded by the Infection Control Department. Data were classified as per the Epinet (University of Virginia) format on the basis of job category, department, device type, procedure involved, injury depth, time since initiating PEP following NSI, prescribed regimen, and follow-up status. ELISA, which confirms HIV infection, was performed immediately and at the sixth month post-exposure. On reporting to the ED, possible sources were identified and confirmed by a serology test for communicable diseases for both health care workers and the patient source.

NSIs are defined as injuries caused by an object such as hypodermic needles, IV cannulas, blood collection needles, suture needles, winged IV sets, and needles used to connect parts of IV delivery systems (6). The severity of injury was defined as a superficial (surface scratch and absence of bleeding), moderate (penetration of skin and bleeding), or deep (deep puncture or wound with or without bleeding (5)). PEP consisted of first aid, counseling, risk assessment, and short-term courses of anti-retroviral given for 30 days, along with follow-up and evaluation.

\section{Statistical analysis}

The Statistical Package for Social Science version 20 (IBM SPSS Statistics, New York; USA) was used for data analysis. Descriptive statistics were used to determine the frequency and percentage of occupational exposure. Logistic regression was used to find the association of the variables with HIV exposure. Tables and graphs are used to present the results.

\section{Results}

A total of 949 cases were reported from 2006 to 2014, and the highest incidence was noted in 2014 (15.2\%) (Figure 1). Overall, there was a significant preponderance of the occurrence of NSIs among staff nurses (42.9\%), followed by nursing assistants, and housekeepers with $16.9 \%$ and $9.2 \%$, respectively. The incidence rate among doctors in our study was comparatively low (5\%) (Figure 2).

The highest incidence rate of NSIs was reported in the patient room/ward (32.5\%), followed by the dental clinic (18.1\%) and ICU (18\%). In total, $67.7 \%$ of the sustained NSIs were moderately deep, while $22.6 \%$ of injuries were superficial. The types of needles causing the NSIs were

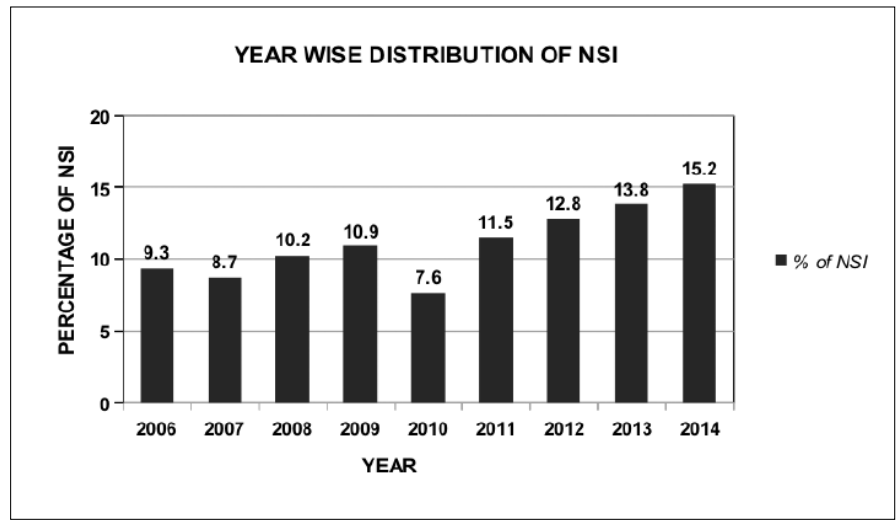

Figure 1. Distribution of the incidence of needlestick injuries by year

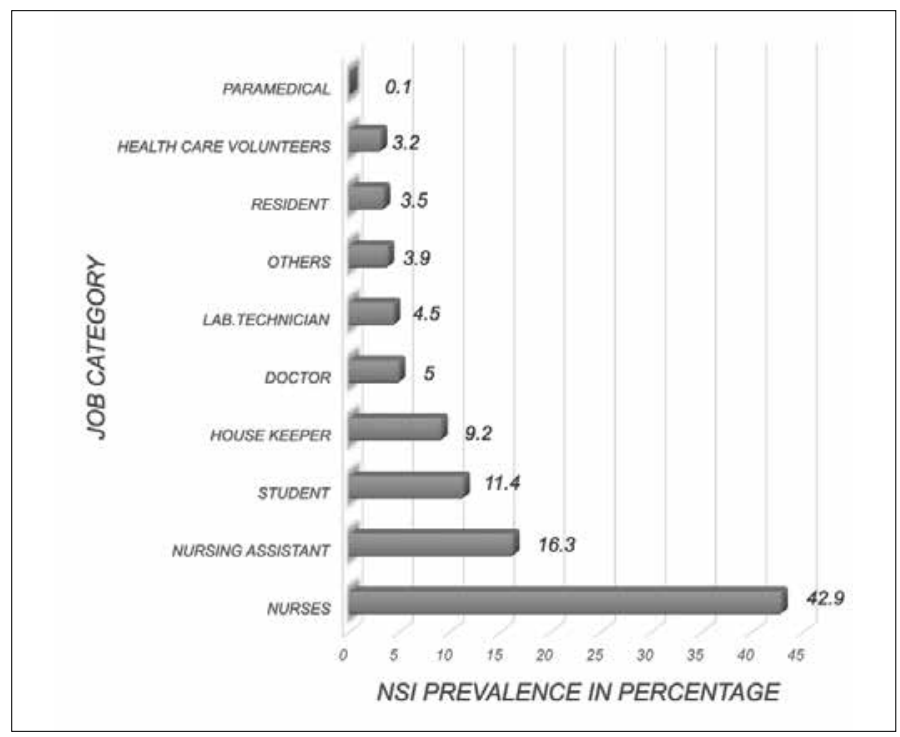

Figure 2. Prevalence of needlestick injuries among health care providers

hypodermic needles (36.7\%), disposable syringes (14.9\%), and intravenous catheters (10\%), followed by other needles (Table 1 ).

Most NSIs reported were during "post-procedure work-up" (64\%), of which $22.4 \%$ of NSIs occurred "during manipulation after procedure" and $9.7 \%$ during recapping, while $36 \%$ occurred "during the procedure," of which $19.8 \%$ were during the use of needles (Table 2 ).

A total of $32 \mathrm{HPs}$ of the 949 cases had received NSIs from known HIV seropositive patients, of which $62.5 \%$ of the HPs were staff nurses. In total, $84.4 \%$ of the HIV exposure cases following NSIs comprised female HPs. The mean age of HPs who received NSIs from known HIV seropositive patients were 26.6 years (Table 3 ). The commonest device involved was the hypodermic needle (65.6\%) (Table 4). The greatest number of HIV exposure cases due to NSIs, occurred in the ICU (40.6\%).

All the 28 cases were initiated on triple-drug ART, containing tenofovir $300 \mathrm{mg}$, emtricitabine $200 \mathrm{mg}$, and efavirenz $600 \mathrm{mg}$, taken orally, once daily, $2 \mathrm{~h}$ after food at night time for 30 days. Four of the HPs deferred due to the fear of side effects. All the HPs at risk were asked to do HIV ELISA on the day of sustaining the NSIs, followed by HIV-RNA PCR two weeks after the NSIs, and HIV ELISA during follow-up at 1 month and 6 months, respectively, and no seropositivity was reported in any of the cases. 
Table 1. Properties of needlestick injuries

\begin{tabular}{|c|c|c|}
\hline $\begin{array}{l}\text { Section-wise } \\
\text { Distribution of } \\
\text { Needlestick Injuries }\end{array}$ & Frequency & $\%$ \\
\hline - Patient Room/Ward & 308 & 32.5 \\
\hline - Dental Clinic & 172 & 18.1 \\
\hline - Intensive Care Unit & 171 & 18.0 \\
\hline - Procedure Room & 73 & 7.7 \\
\hline - Out Patient Clinic & 60 & 6.3 \\
\hline - Emergency Department & 49 & 5.2 \\
\hline - Other Describe & 42 & 4.4 \\
\hline - Service/Utility & 29 & 3.1 \\
\hline - Clinical Laboratories & 25 & 2.6 \\
\hline - Outside Patient Room & 15 & 1.6 \\
\hline - Dialysis Unit & 5 & 0.5 \\
\hline \multicolumn{3}{|l|}{ Depth of Injury } \\
\hline - Superficial & 226 & 23.8 \\
\hline - Moderate & 629 & 66.3 \\
\hline - Severe & 94 & 9.9 \\
\hline \multicolumn{3}{|l|}{$\begin{array}{l}\text { Devices Associated with } \\
\text { Needlestick Injuries }\end{array}$} \\
\hline - Hypodermic Needle & 348 & 36.7 \\
\hline - Syringe Disposable & 141 & 14.9 \\
\hline - Intravenous Catheter & 95 & 10 \\
\hline - Needle Holder/Vacuum Tube & 82 & 8.6 \\
\hline - Suture Needle & 82 & 8.6 \\
\hline - Vacuette Needle & 54 & 5.7 \\
\hline - Intravenous Stylet & 39 & 4.1 \\
\hline - Needle On Intravenous Tubing & 31 & 3.3 \\
\hline - Syringe, Prefilled Cartridge & 28 & 3 \\
\hline - Needle, Other Vascular Catheter & 17 & 1.8 \\
\hline - Butterfly Needle & 14 & 1.5 \\
\hline - Needle Described & 8 & 0.8 \\
\hline - Needle Unknown Type & 5 & 0.5 \\
\hline - Syringe, Other Type & 3 & 0.3 \\
\hline - Trocar & 2 & 0.2 \\
\hline Total & 949 & 100 \\
\hline
\end{tabular}

On a logistic regression of variables with HIV exposure, the only variable significantly associated with HIV exposure was the job category of the HP. Staff nurses were proven to have 1.56 times more risk compared to the other $\mathrm{HPs}(\mathrm{OR}=1.56,95 \% \mathrm{Cl} 0.58-4.19, \mathrm{p}=0.026)$.

\section{Discussion}

From a literature search, only a few hospital-based studies on the incidence of NSIs among HPs in South India could be obtained.
Table 2. Procedures associated with needlestick injuries

\begin{tabular}{|c|c|c|}
\hline Procedure & Frequency & $\%$ \\
\hline \multicolumn{3}{|l|}{ During the Procedure } \\
\hline During the use of needles & 188 & 19.8 \\
\hline Blood collection & 44 & 4.6 \\
\hline $\begin{array}{l}\text { Between steps of a multi-step } \\
\text { procedure }\end{array}$ & 25 & 2.6 \\
\hline Intravenous line insertion & 26 & 2.7 \\
\hline During surgery & 20 & 2.1 \\
\hline Checking random blood sugar & 18 & 1.9 \\
\hline Giving injection & 10 & 1.1 \\
\hline Cleaning & 6 & 0.6 \\
\hline Suturing & 4 & 0.4 \\
\hline $\begin{array}{l}\text { Withdrawing a needle from } \\
\text { rubber or other resistance }\end{array}$ & 2 & 0.2 \\
\hline \multicolumn{3}{|l|}{ After the Procedure } \\
\hline $\begin{array}{l}\text { Manipulation after use before } \\
\text { disposal }\end{array}$ & 213 & 22.4 \\
\hline Recapping & 92 & 9.7 \\
\hline $\begin{array}{l}\text { Device left on the floor, table, } \\
\text { bed or other place }\end{array}$ & 67 & 7.1 \\
\hline $\begin{array}{l}\text { After disposal protruding from } \\
\text { disposal }\end{array}$ & 26 & 2.7 \\
\hline $\begin{array}{l}\text { Item pierced the side of } \\
\text { disposal container }\end{array}$ & 23 & 2.4 \\
\hline $\begin{array}{l}\text { While putting items into the } \\
\text { disposal container }\end{array}$ & 45 & 4.7 \\
\hline Waste collection & 16 & 1.7 \\
\hline Disassembling device & 10 & 1.1 \\
\hline In preparation for reuse of reusable & 3 & 0.3 \\
\hline $\begin{array}{l}\text { From items left on the floor } \\
\text { near a disposal container }\end{array}$ & 2 & 0.2 \\
\hline Others & 109 & 11.5 \\
\hline Total & 949 & 100.0 \\
\hline
\end{tabular}

Table 3. Distribution of HIV exposure among health care providers

\begin{tabular}{|l|c|c|}
\hline Job Category & Number & \% \\
\hline Staff Nurse & 20 & 62.5 \\
\hline Doctors & 5 & 15.6 \\
\hline Nursing Students & 3 & 9.4 \\
\hline Nursing Assistants & 4 & 12.5 \\
\hline Total & 32 & 100 \\
\hline
\end{tabular}

A total of 949 self-reported cases of NSIs from January 2006 to December 2014 were recorded, with the incidence of NSIs increasing over the years. The increased incidence of NSIs among HPs can be explained by the circumstances/procedures during which the exposure had occurred, ineffective in-service education and training on 
Table 4. Devices and HIV exposure

\begin{tabular}{|l|c|c|}
\hline Type of Device & Number & \% \\
\hline Hypodermic needle & 21 & 65.6 \\
\hline IV stylet & 7 & 21.9 \\
\hline Vacuette needle & 2 & 6.3 \\
\hline K wire & 1 & 3.1 \\
\hline Prefilled cartridge & 1 & 3.1 \\
\hline Total & 32 & 100.0 \\
\hline
\end{tabular}

the use of person protection equipment, relative inexperience, and negligence from the HP. All HPs, after recruitment, are given initial training in infection control and waste management.

In the present study, the incidence of NSIs in a calendar year was only 105.4 HP, which could be explained by some underreporting. The main reasons for underreporting might be due to the fact that a significant proportion of HPs did not know about the existence of a PEP service and were unaware about whom to contact in the event of an occupational exposure. Other reasons include an underestimation of HIV transmission and an unwillingness to take anti-retroviral drugs, as has been noted in previous studies (7-12).

In the present study, majority of NSIs were reported by staff nurses, $(42.9 \%)$, which is a similar result compared with previous studies $(4,6,13-16)$. This incidence rate is high though compared with a study done by Jayanth et al. (17), where $28 \%$ of nurses had experienced NSIs. In the present study, it was revealed that students (11.4\%) were found to have a higher incidence rate than doctors, probably due to their lack of awareness of occupational exposure to blood pathogens and lack of training on the use of personal protection equipment. Nursing assistants (16.3\%) were also found to have a significant proportion of NSIs, probably because they were not involved in awareness programs (18-21).

In the present study, majority of NSIs occurred in patient rooms $(32.5 \%)$, which was consistent with the observations made by Guo et al. (22) (38\%) but differs from results of other studies, where the highest percentage of NSIs were observed in the minor operation theater and emergency operation theater $(18,23)$. The present study reveals that the maximum number of NSIs occurred during the "post-procedure" work-up from used needles (64\%) compared to the "during procedure" work-up (36\%). In the post-procedural work-up, "manipulation after use before disposal" (22.4\%) had the highest incidence rate, probably because of a lack of technical preparation, distraction, and working in a hurry. In our study, NSIs during recapping had an incidence rate of $9.7 \%$, which is in concordance with a study conducted by Yoshikawa et al. (24). Despite the existence of "universal precautions" since 1987 to prevent NSIs due to the recapping of needles, the incidence rate of NSIs due to recapping remains high (66.3\%) among HPs in India (25). In total, $2.4 \%$ of the NSIs occurred due to the needle piercing the disposal container, which underlines the need for puncture-proof disposal containers. The commonest device involved was the hypodermic needle (36.7\%); this fining was similar to the observations made by Radha et al. (4) (44\%) (18). Studies regarding the depth of injury are rarely reported in India. In the current study, majority of pricks were moderately deep (66.3\%). Superficial injuries (23.8\%) were found in only $23.2 \%$.

Of the total of 949 cases, 32 (3.47\%) were found to have NSIs from HIV seropositive patients. These findings were less when com- pared to observations made by Kumakech et al. (26) in the UK, in which $8.93 \%$ were exposed to HIV through NSIs. This difference in the incidence rate was probably due to the higher prevalence of HIV in western countries. In the present study, $84.4 \%$ of HIV exposures to NSIs comprised female HPs, with a mean age of $26.6 \pm 6.0$ years, which is a similar result to that of the study conducted by McEvoy et al. (27), where $50 \%$ of the HPs were below 25 years of age. This may be due to the relative work inexperience of the staff. Staff nurses (62.5\%) acquired the maximum exposure to HIV due to NSIs, which can be explained by the circumstances/procedures during which exposure would have occurred. Similar observations were made by Kumakech et al. (26) and McEvoy et al. (27), where $61 \%$ of staff nurses were exposed. In the present study, the incidence rate of NSIs among doctors was $15.6 \%$, which is less compared to the study conducted by McEvoy et al. (27) (21\%). The commonest device involved was the hypodermic needle $(65.6 \%)$, for which no comparative study data could be obtained. The greatest number of HIV exposure due to NSIs occurred in the ICU (40.6\%), similar to the observations made by Kumakech et al. (26), in which $46.8 \%$ occurred in medical and surgical wards. van der Maaten et al. (7) reported the highest incidence of NSIs in the obstetrics ward. Observations made in the UK and China, where physicians were not available around the clock and non- of anti-retroviral medications, had reported significant underreporting and improper PEP delivery $(7,17)$.

The mean duration between initiating PEP and occupational injury was $2.8 \mathrm{~h}$ in the current study, but it was found to be $7.6 \mathrm{~h}$ in a previous study (28). This may be due to the availability of an ER physician $24 \mathrm{~h}$ a day and 7 days a week who could counsel HPs and prescribe anti-retroviral medications.

Among the 32 HPs who received NSIs from HIV seropositive patients, 28 were initiated on triple-drug therapy, which consisted of tenofovir 300 mg, emtricitabine 200 mg, and efavirenz 600 mg taken orally, once daily, $2 \mathrm{~h}$ after food at night for 30 days. Four HPs deferred due to the fear of side effects. All HPs at risk were asked undergo HIV ELISA on the day of receiving the NSI, followed by HIV-RNA PCR 2 weeks after receiving the NSI, and HIV ELISA during follow-up at 1 month and 6 months, respectively, and no seropositivity was reported.

\section{Conclusion}

The present study shows the high prevalence of NSIs among HPs, particularly among staff nurses. HPs have always been known to be at risk of contracting acquired infectious diseases. In light of new emerging communicable diseases with new or unknown pathogens as causative agents, the prevention of NSIs among HPs has acquired significant value. Periodic health education campaigns should be promoted, and strict adherence to standard precautionary protocols should be made mandatory to prevent and minimize the incidence of NSIs among HPs. Periodic updates about PEP should also be made to raise awareness among HPs.

Ethics Committee Approval: Ethics committee approval was received for this study from the ethics committee of Amrita Vishwa Vidyapeetham University.

Peer-review: Externally peer-reviewed. 
Conflict of Interest: No conflict of interest was declared by the authors.

Financial Disclosure: The authors declared that this study has received no financial support.

\section{References}

1. Prüss-Ustün A, Rapiti E, Hutin Y. Estimation of the global burden of disease attributable to contaminated sharps injuries among health-care workers. Am J Ind Med 2005; 48: 48-90. [CrossRef]

2. Tarantola A, Abiteboul D, Rachline A. Infection risks following accidental exposure to blood or body fluids in health care workers: a review of pathogens transmitted in published cases. Am J Infect Control 2006; 34: 367-75. [CrossRef]

3. Bryant J, Baxter L, Hird S. Non-occupational postexposure prophylaxis for HIV: a systematic review. Health Technol Assess 2009; 13: 1-60. [CrossRef]

4. Radha R, Khan A. Epidemiology of needle stick injuries among the healthcare workers of rural tertiary care hospital - A cross sectional study. Nat J Community Med 2012; 3: 589-94.

5. Cardo DM, Culver DH, Ciesielski CA, Srivastava PU, Marcus R, Abiteboul D, et al. A case-control study of HIV seroconversion in health care workers after percutaneous exposure. N Engl J Med 1997; 337: 1485-90. [CrossRef]

6. Hashmi A. Prevalence of Needle-stick and Sharps Injuries among Healthcare Workers, Najran, Saudi Arabia. Epidemiology: Open Access. 2012: 117. DOI:10.4172/2161-1165.1000117. [CrossRef]

7. van der Maaten GC, Nyirenda M, Beadsworth MJ, Chitani A, Allain T, van Oosterhout JJ. Post exposure prophylaxis of HIV transmission after occupational injuries in Queen Elizabeth Central Hospital, Blantyre, Malawi, 2003-2008. Malawi Med J 2010; 22: 15-9. [CrossRef]

8. Lin C, Li L, Wu Z, Wu S, Jia M. Occupational exposure to HIV among health care providers: A Qualitative study in Yunnan, China. J Int Assoc Physicians AIDS Care (Chic) 2008; 7: 35-41.

9. Gumodoka B, Favot I, Berege ZA, Dolmans WM. Occupational exposure to the risk of HIV infection among health care workers in Mwanza Region, United Republic of Tanzania. Bull. Bull World Health Organization. 1997;75:133-140.

10. Abdel-Malek ZA, Kadekaro AL, Kavanagh RJ, Todorovic A, Koikov LN, McNulty JC, et al. Melanoma prevention strategy based on using tetrapeptide alpha-MSH analogs that protect human melanocytes from UV-induced DNA damage and cytotoxicity. FASEB J 2006; 20: 1561-3. [CrossRef]

11. Haiduven DJ, Simpkins SM, Phillips ES, Stevens DA. A survey of percutaneous/ mucocutaneous injury reporting in a public teaching hospital. Journal of Hosp Infect 1999; 41: 151-4. [CrossRef]

12. Sohn S, Eagan J, Sepkowitz KA. Safety engineered device implementation: does it introduce bias in percutaneous injury reporting? Infect Control Hosp Epidemiol 2004; 25: 532-5.

13. Falagas ME, Karydis I, Kostogiannou I. Percutaneous exposure incidents of the health care personnel in a newly founded tertiary hospital: a prospective study. PLoS One 2007; 2: e194.
14. Foley M. Update on needlestick and sharps injuries: the Needle Stick Safety and Prevention Act of 2000. Am J Nurs 2004; 104: 96. [CrossRef]

15. Tan L, Hawk JC, Sterling ML. Report of the Council on Scientific Affairs: preventing needlestick injuries in health care settings. Arch Intern Med 2001; 161: 929-36. [CrossRef]

16. Katkuri S, Begum S. Occupational Exposure to Blood and Body Fluids Among Health Care Workers in Teaching Hospital, Hyderabad, India. J Pharm Biomed Sci 2015; 5: 95-9.

17. Jayanth ST, Kirupakaran H, Brahmadathan KN, Gnanaraj L, Kang G. Needle stick injuries in a tertiary care hospital. Indian J Med Microbiol 2009; 27: 44-7.

18. Gilks CF, Wilkinson D. Reducing the risk of nosocomial HIV infection in British health worklers working overseas: role of postexposure prophylaxis. BMJ 1998; 316: 1158-60. [CrossRef]

19. Reis JMB, Lamounier Filho A, Rampinelli CA, Soares ECS, Prado RS, Pedroso ERP. Training-related accidents during teacher-student-assistance activities of medical students. Rev Soc Bras Med Trop 2004; 37: 405-8. [CrossRef]

20. Salzer HJ, Hoenigl M, Kessler HH, Stigler FL, Raggam RB, Rippel KE, et al. Lack of risk-awareness and reporting behavior towards HIV infection through needlestick injury among European medical students. Int J Hyg Environ Health 2011; 214: 407-10. [CrossRef]

21. Sharma GK, Gilson MM, Nathan H, Makary MA. Needlestick injuries among medical students: incidence and implications. Acad Med 2009; 84: 1815-21. [CrossRef]

22. Guo YL, Shiao J, Chuang YC, Huang KY. Needlestick and sharps injuries among health-care workers in Taiwan. Epidemiol Infect 1999; 122: 25965. [CrossRef]

23. Souza-Borges FRF de, Ribeiro LA, Oliveira LCM. Occupational exposures to body fluids and behaviors regarding their prevention and post-exposure among medical and nursing students at a Brazilian public university. Rev Inst Med Trop 2014; 56: 157-63. [CrossRef]

24. Yoshikawa T, Wada K, Lee JJ, Mitsuda T, Kidouchi K, Kurosu H, et al. Incidence rate of needlestick and sharps injuries in 67 Japanese hospitals: a national surveillance study. PLoS One 2013; 8: e77524.

25. Muralidhar S, Singh PK, Jain RK, Malhotra M, Bala M. Needle stick injuries among health care workers in a tertiary care hospital of India. Indian J Med Res 2010; 131: 405-10.

26. Kumakech E, Achora S, Mbchb FB. Occupational exposure to HIV: a conflict situation for health workers. Int Nurs Rev 2011; 58: 454-62. [CrossRef]

27. McEvoy M, Porter K, Mortimer P, Simmons N, Shanson D. Prospective study of clinical, laboratory, and ancillary staff with accidental exposures to blood or body fluids from patients infected with HIV. Br Med J (Clin Res Ed) 1987; 294: 1595-7. [CrossRef]

28. Chen M, Fox E, Rogers C. Post-exposure prophylaxis for human immunodeficiency virus: knowledge and experience of junior doctors. Sex Transm Infect 2001; 77: 444-5. [CrossRef] 